OPEN ACCESS

Edited by:

Peter John Shortland,

Western Sydney University, Australia

Reviewed by:

Ping Yip,

Queen Mary University of London, United Kingdom

Bizhan Aarabi,

University of Maryland, Baltimore

United States

${ }^{*}$ Correspondence:

Samira Saadoun

ssaadoun@sgul.ac.uk

Specialty section:

This article was submitted to

Neurotrauma

a section of the journal

Frontiers in Neurology

Received: 14 November 2020

Accepted: 04 January 2021

Published: 03 February 2021

Citation:

Saadoun S and Jeffery ND (2021) Acute Traumatic Spinal Cord Injury in Humans, Dogs, and Other Mammals:

The Under-appreciated Role of the

Dura. Front. Neurol. 12:629445.

doi: 10.3389/fneur.2021.629445

\section{Acute Traumatic Spinal Cord Injury in Humans, Dogs, and Other Mammals: The Under-appreciated Role of the Dura}

\author{
Samira Saadoun ${ }^{1 *}$ and Nicolas D. Jeffery ${ }^{2}$ \\ 'Academic Neurosurgery Unit, St. George's, University of London, London, United Kingdom, ${ }^{2}$ Department of Small Animal \\ Clinical Sciences, Texas A\&M University, College Station, TX, United States
}

We review human and animal studies to determine whether, after severe spinal cord injury (SCl), the cord swells against the inelastic dura. Evidence from rodent models suggests that the cord swells because of edema and intraparenchymal hemorrhage and because the pia becomes damaged and does not restrict cord expansion. Human cohort studies based on serial MRIs and measurements of elevated intraspinal pressure at the injury site also suggest that the swollen cord is compressed against dura. In dogs, $\mathrm{SCl}$ commonly results from intervertebral disc herniation with evidence that durotomy provides additional functional benefit to conventional (extradural) decompressive surgery. Investigations utilizing rodent and pig models of SCl report that the cord swells after injury and that durotomy is beneficial by reducing cord pressure, cord inflammation, and syrinx formation. A human MRI study concluded that, after extensive bony decompression, cord compression against the dura may only occur in a small number of patients. We conclude that the benefit of routinely opening the dura after SCl is only supported by animal and level III human studies. Two randomized, controlled trials, one in humans and one in dogs, are being set up to provide Level I evidence.

Keywords: animal, dog, dura, duroplasty, durotomy, human, spinal cord injury, surgery

\section{INTRODUCTION}

This review discusses acute traumatic spinal cord injury (SCI) with emphasis on cord swelling. We compare SCI in various mammals and present evidence for and against the notion that, after SCI, the cord swells against the dura. We then discuss two randomized, controlled trials (RCTs) being set up to define the role of the dura in human and dog SCI.

\section{SPINAL CORD INJURY IN MAMMALS}

\section{Humans}

SCI is a devastating condition affecting about 180,000 patients annually worldwide (1). The commonest causes are road traffic accidents, sport injuries and falls. In younger patients, SCI is often associated with fracture or dislocation. Many older patients develop 'central cord syndrome', a type of cervical incomplete SCI that occurs with pre-existing canal stenosis often in the absence of a fracture, causing primarily upper limb weakness (2). After SCI, most patients remain neurologically impaired with limb weakness or paralysis, loss of sensation below the injury, impaired urination, 
defecation and sexual function (3). To date, there is no treatment in clinical use proven to improve outcome after SCI.

\section{Dogs}

SCI is commonly seen in dogs: veterinary clinics with appropriate imaging and surgical facilities treat $>200 \mathrm{dog}$ SCI cases per year and there are $>200$ such centers in the USA alone (4). The commonest cause of SCI is intervertebral disc prolapse, often occurring between T11-L3 vertebrae. Disc prolapse occurs in all dogs but is most common in chondrodystrophic individuals and so is especially prevalent in small breeds, notably the dachshund $(5,6)$. Susceptibility to disc degeneration is gene- and family-associated, with some dachshund families having $>50 \%$ symptomatic individuals (7) and specific genetic determinants have recently been identified $(8,9)$. The severity of SCI varies, but about $20 \%$ of the total develop complete motor and sensory loss below the level of a thoracolumbar lesion (10). Furthermore, $10-15 \%$ of dogs with acute complete loss of motor and sensory function develop progressive myelomalacia, which appears almost unique in this species $(11,12)$. Progressive myelomalacia causes loss of neurological function that progresses caudally (to affect the hind limb reflex centers), cranially (to affect the intercostal muscle innervation or even the forelegs) or both. The cause is unknown, though imaging and postmortem examination support progressive vascular injury and hemorrhage (13).

\section{Other Mammals}

Our knowledge of SCI in other mammals is derived from their use in research. SCI is predominantly modeled in rodents, although some centers investigate primates, primarily because they provide better read-outs of hand function (14) and an increasing number utilize pigs (15). Most animal models (AMs) are contusive, dropping a weight or using an impactor on the cord. Other AMs are compressive, applying an aneurysm clip to the cord, compressing the cord with forceps or inflating a balloon to achieve contusion-compression injury. The clinical relevance of transection injury AMs is doubtful, since most human SCIs are contusive-compressive. For further details, see recent reviews $(16,17)$.

\section{SURGICAL TREATMENT}

\section{Humans}

Mild SCIs may be managed conservatively. For severe SCI, conservative management was advocated in the early and mid-twentieth century (18), but the current trend is early surgery to eliminate the extradural cord compression and spinal instrumentation to stabilize the spine and prevent further cord damage. Whether early bony decompression improves neurological outcome is controversial (19-21). For central cord syndrome, some surgeons advocate surgical decompression, but others manage conservatively, without incontrovertible evidence favoring either approach (2).

\section{Dogs}

There are two management options for dogs with acute SCI: conservative care with restriction of exercise for a few weeks or cross-sectional imaging (CT, MRI) and decompressive surgery (22). Conservative therapy is reserved for dogs with mild neurologic deficits or pain alone. Decompressive surgery aims to remove the extruded disc from the epidural space through "hemilaminectomy" (23), which has been the dominant surgical approach for the past 60-70 years, although more recent modifications have been described $(24,25)$. It is important to recognize progressive myelomalacia before it affects the phrenic nucleus in the cervical region, thereby causing suffocation, so that affected dogs can be euthanatized. Progressive myelomalacia is usually apparent within the first week after SCI and its development can be monitored by repeated examination of the panniculus (cutaneous trunci) muscle reflex (26).

\section{EVIDENCE THAT THE DURA PLAYS A KEY ROLE}

\section{Humans}

Spinal cord swelling is common after SCI with evidence that the amount of swelling, e.g., longitudinal cord signal change on T2 MRI, correlates with outcome (27). In a cohort of 65 SCI patients without bony compression, the extent of cord swelling against the dura increased with increasing severity of SCI and resolved slowly ( $t_{1 / 2}=9$ days) (28). At St. George's Hospital, we insert intradurally at the injury site a pressure probe to monitor intraspinal pressure (ISP) and spinal cord perfusion pressure (SCPP) at the injury site $(29,30)$. SCPP is mean arterial pressure minus ISP, analogous to cerebral perfusion pressure for brain injury. A key finding is that ISP remains high with low SCPP even after anterior and posterior bony decompression $(29,30)$ thus suggesting that the dura contributes to cord compression. ISP is generally high at the injury site with lower cerebrospinal fluid (CSF) pressure cranially and caudally, even after bony decompression (30-32). This finding suggests cord swelling against the dura at the injury site that results in three intradural compartments (Figure 1A): injury site (swollen cord compressed against dura), CSF compartment above and CSF compartment below the injury (34). Lumbar CSF pressure monitoring also supports the notion of cord compression against the dura at the injury site, because the lumbar CSF pressure signal is often non-pulsatile and because attempts to withdraw CSF result in a "dry tap" (32, 35, 36). An exploratory study (33) assessed safety and the effect on ISP and SCPP of duroplasty after SCI (Figure 1B) by comparing bony decompression in 11 patients vs. bony plus dural decompression in 10 (Figures 1C,D). Duroplasty was safe: $50 \%$ patients had no complications and $50 \%$ had noncompressive pseudo-meningocele that disappeared at 6 months, with no wound infection, no persistent cerebrospinal fluid (CSF) leak and no worsening neurological deficits. Compared with bony decompression alone, bony plus dural decompression significantly reduced ISP and increased SCPP. After bony decompression alone, $40 \%$ of the time, SCPP was very low $(<60$ 

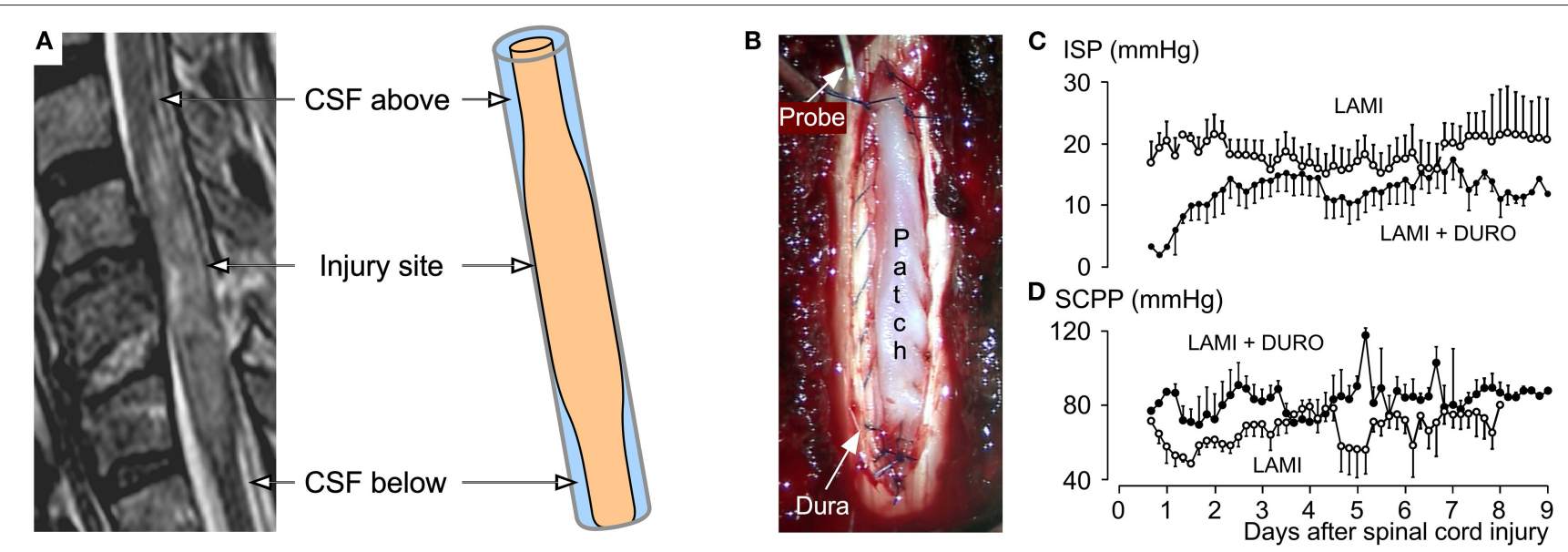

FIGURE 1 | Intradural compartments after SCI and expansion duroplasty in humans. (A) (left) MRI and (right) Schematic: the three compartments are injury site (swollen cord compressed against dura), CSF above injury, CSF below the injury. (B) Sutured duroplasty patch and intradural pressure probe. (C) ISP (mean \pm S.D.) and (D) SCPP (mean \pm S.D.) vs. days after injury for 11 patients who had bony decompression plus stabilization (LAMI) and 10 patients who had bony decompression plus duroplasty plus stabilization (LAMI + DURO). Based on Phang et al. (33).

mmHg likely to cause ischemic damage), compared with $<5 \%$ of the time after bony plus dural decompression. A RCT is required to determine whether these improved physiological parameters at the injury site (lower ISP, higher SCPP) achieved by bony plus dural decompression improve functional outcomes. There are other reports of SCI patients treated with bony decompression plus duroplasty claiming improved outcome but without control patient groups $(37,38)$. SCI may be analogous to traumatic brain injury (TBI) where decompressive craniectomy requires not only bony but also dural decompression. The effectiveness of combined bony-dural decompression as a life-saving procedure after TBI has been shown in the RESCUEicp RCT (39). Overall, the SCI studies provide Level III evidence that duroplasty is beneficial.

\section{Dogs}

Spinal cord swelling accompanies acute disc herniation in dogs, evident on myelography and MRI as loss of CSF signal (Figures 2A,B). Some studies suggest that the length of cord swelling on MRI (41) or extent of T2W hyperintensity within the cord (42) have prognostic value, though such analyses are confounded by lack of knowledge of the time between insult and scan. More recently, regions of T2W hypo-intensity have been shown to correlate well with failure to recover (13). The cord swelling after SCI raises the possibility that durotomy may reduce cord pressure thus improving cord perfusion (Figures 2C,D). Durotomy was initially used in experimental SCI in dogs and a benefit was suggested (43). Since then, durotomy has been reported sporadically by veterinarians (44, 45). Between 1950 and 1980, durotomy after acute SCI was primarily used as a prognostic tool for dogs in which there was acute complete sensorimotor loss (46). The dura was incised to evaluate cord consistency: animals with myelomalacia were considered irretrievable and thus euthanatized. In dogs the preferred procedure has hitherto been durotomy without duroplasty, because CSF leak has not been an issue.

In the past year, two reports on the use of durotomy for severe thoracolumbar SCI in dogs have been published $(47,48)$. Neither is a RCT, although the "baseline" rate of recovery for motor and sensory complete dogs is well-known (49-51). In one report, all dogs with motor and sensory complete SCI received a 4-vertebral length durotomy (48). This length was selected as a compromise between the typical length of loss of CSF signal on MRI/myelography and the need to minimize surgical time. At 6 months, 16 of the dogs recovered to walk, 6 did not recover (of which one developed progressive myelomalacia) and 4 were lost to follow-up. A comparison to expected recovery with Bayesian analysis suggested high likelihood of improved results over non-durotomy surgery.

The second study (47) included dogs with especially severe injuries: no pain perception in the hindlimbs plus extended region of T2W hyperintensity on preoperative MRI (42). Allocation into two groups was made according to the date of presentation. 25/65 (39\%) dogs in the non-durotomy (control) surgery group recovered to walk vs. 29/51 (57\%) dogs in the durotomy group. None of the dogs in the durotomy group developed progressive myelomalacia vs. 14/65 (22\%) dogs in the control group. The length of durotomy was not specified.

\section{Other Mammals}

In a mouse SCI model (40), which involves laminectomy and thoracic cord compression, the cord swelled against dura as evidenced by myelography (Figures 2E-G). ISP $48 \mathrm{~h}$ postSCI was 30 vs. $10 \mathrm{mmHg}$ in sham-operated mice. Since the mice had laminectomies, the high ISP must represent cord swelling against the dura. Reduced cord swelling in AQP4-null mice with SCI, evidenced by reduced ISP, was associated with improved neurological outcome assessed by footprint analysis, slope climbing and evoked potentials. There is now evidence 

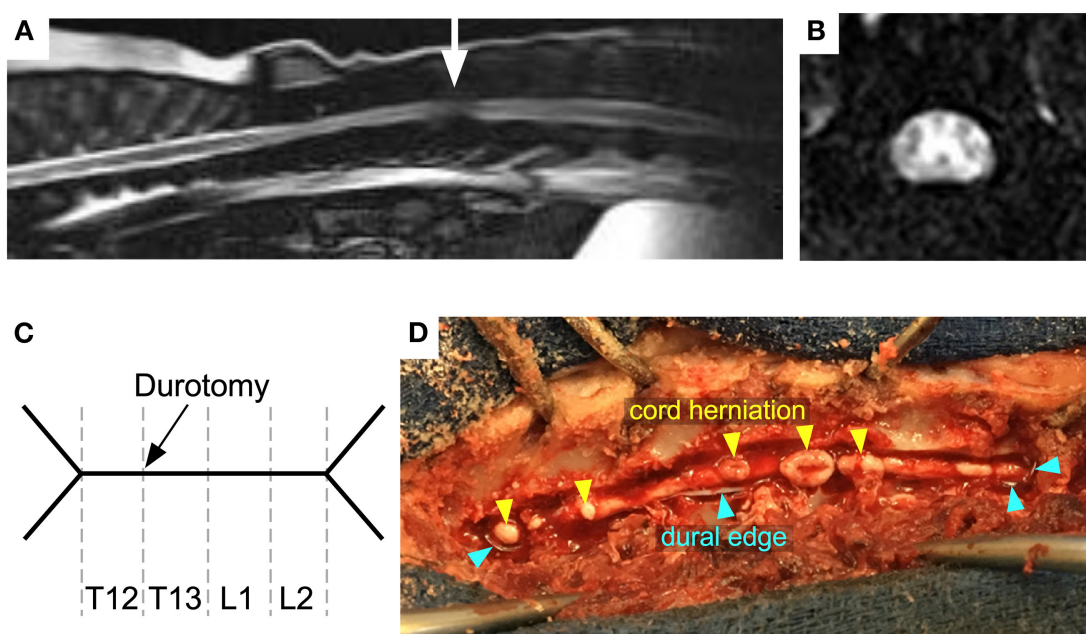

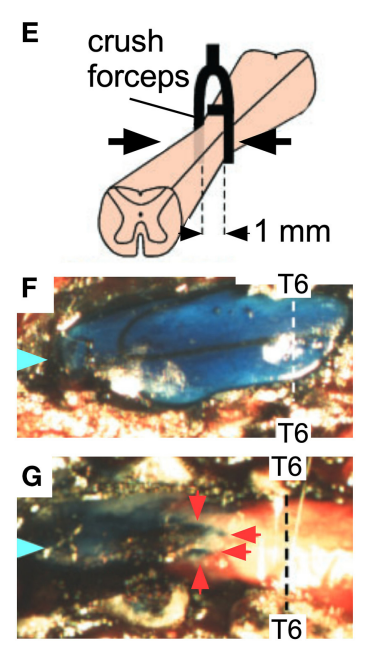

FIGURE 2 | SCl in dogs and mice. (A) Sagittal, and (B) axial MRI of disc herniation at thoracolumbar junction (arrow) with cord swelling and cord compression against dura (loss of CSF signal around cord). (C) Schematic of durotomy in dog, Y-shaped at each end and extending over 4 spinal levels. (D) Dog cord herniation after dural opening. (E) Schematic showing forceps with spacer compressing mouse cord at T6. Exposed theca in (F) sham and (G) injured mice at 2 days after surgery: Evans blue dye was injected intracisternally (Blue arrows mark cranial end, red arrows indicate obstruction preventing the flow of dye). Adapted from (40).

from several SCI models in different species, including rat impact (52), rabbit balloon (53), and pig stretch (54) SCI models that, after the injury, the cord swells generating high ISP without bony compression. The degree of cord swelling depends on species, severity of injury, spinal level and mechanism of injury. Durotomy reduced ISP in stretched ex vivo pig cords from 35 to $10 \mathrm{mmHg}$ (54). In a rat SCI impact model, duroplasty improved the walking score compared with no duroplasty and also reduced syrinx size (55). This finding suggests that duroplasty has additional benefit to reducing ISP; by reducing cord tethering to dura thus preventing syrinx formation. In a rat weight-drop SCI study, duroplasty led to white matter sparing compared with laminectomy (56). The above studies suggest that opening the dura after SCI is beneficial in multiple species and injury models.

A comparison of durotomy vs. duroplasty in rat contusion $(55,57)$ and rat compression (58) SCI models revealed reduced lesion volume with duroplasty because of less inflammation and less collagen scarring in the duroplasty group. In humans, duroplasty is preferred to durotomy because duroplasty reduces the risk of CSF leak through the wound but, in dogs, durotomy is more commonly performed. In a rat SCI study in which duroplasty initially appeared detrimental, it turned out that use of fibrin sealant swelled and caused cord compression (56). We thus advise against using fibrin sealants after duroplasty.

\section{CAUSES OF SPINAL CORD SWELLING}

In a balloon SCI model in rabbits, intraparenchymal hemorrhage developed within 5 hours and was the primary cause of cord swelling whereas edema became the primary cause of cord swelling at 5-7 days post-injury (59). Intraparenchymal hemorrhages and cord edema are also evident in human SCI and the length of cord edema and the length of intraparenchymal hemorrhage on MRI (27) as well the mean intraspinal pressure
(60), monitored in the first week after SCI, correlate with outcome. Extravasation studies in dog models (61) and diffusionweighted human MRI (62) suggest that cord edema after SCI is cytotoxic (cell swelling) and vasogenic (leaky capillaries) with accumulation of excess water intracellularly and interstitially. The water channel protein AQP4 plays a key role in water flow into and out of injured cord with opposing roles in vasogenic (63) vs. cytotoxic edema (40). Although histological studies in humans (64) and rodents (65) show large numbers of inflammatory cells at the injury site, it is unclear whether the volume of these cells contributes to cord swelling. There are, therefore, three causes of cord swelling after SCI: cord hematoma, cord edema and potentially, influx of inflammatory cells.

A key question is whether the swollen cord overcomes the pia to expand against dura. Spinal cords retrieved from fresh cadavers and immersed in water swelled generating intraparenchymal pressures, in the absence of dura, of 73.7 and $49.3 \mathrm{mmHg}$ in the cervical and thoracic regions, respectively, that reduce to 9.7 and $10.3 \mathrm{mmHg}$ post-piotomy (66). These findings suggest that the pia may contribute significantly to high intraparenchymal cord pressure after injury. However, the pia in these cords was intact. In humans with severe SCI, the cord appears expanded against the dura on MRI (28) and ISP is elevated $(29,30)$. In humans the pia is relatively tough; thus, the cord swelling evident on MRI after SCI likely indicates pial damage. This is supported by the observation that in a patient with severe SCI, simultaneously measured ISP and intraparenchymal pressures were elevated and equal (31). These findings suggest that in humans the intact pia is tough enough to limit cord expansion but, after severe SCI, the damaged pia no longer restricts cord swelling. In a compression SCI in rabbits, myelotomy (longitudinal incision of the cord to allow exit of hematoma and dead tissue) plus durotomy reduced ISP and improved histological outcomes compared with 
durotomy without myelotomy (67); however, the ISP was low (5$10 \mathrm{mmHg}$ ) in both animal groups without difference in hindlimb locomotor scores. In another rodent SCI model (68), durotomy alone or durotomy plus myelotomy improved several histological outcomes, but only durotomy alone promoted recovery of ladder walk performance and bladder function. In a rodent study of contusion SCI, the dura and pia contributed almost equally to increased ISP in the first $12 \mathrm{~h}$ but, by three days, the dura was responsible for the elevated ISP with little or no contribution from the pia (52). Based on these reports, the functional advantage of performing myelotomy, in addition to the durotomy, remain unclear with concern that myelotomy may itself produce cord damage.

\section{EVIDENCE AGAINST CORD COMPRESSION BY THE DURA}

An MRI study of 184 motor-complete SCI patients concluded that adequate decompression is achieved in $91 \%$ patients with multi-level laminectomies alone (69). A patient's ISP varies widely $(30,32)$, with periods when lumbar CSF pressure is pulsatile and equals ISP (no cord compression against dura) and periods when lumbar CSF pressure is non-pulsatile and lower than ISP (cord compression against dura). Periods of non-pulsatile lumbar CSF after SCI have been observed by Kwon et al. (35). Thus, cord compression against dura is dynamic, i.e., a single MRI may not adequately assess such compression. In another study (70), laminectomy after SCI was not associated with low ISP. Aarabi et al. (69) proposed that cord compression against the dura may only occur in a small number or patients, provided multi-level laminectomies have been performed.

\section{RANDOMIZED CLINICAL TRIALS}

Based on the above evidence, human and dog phase III studies are being set up to test durotomy as a potential surgical treatment for SCI.

\section{Humans}

The trial, termed DISCUS (Duoroplasty for Injured cervical Spinal Cord with Uncontrolled Swelling), aims to recruit 222 adults with acute, cervical traumatic SCI who have surgery within $72 \mathrm{~h}$. Eligible patients will have American spinal injuries association Impairment Scale (AIS) grade A, B, or C on admission. The patients will be randomized 1:1 to have spinal fixation plus laminectomy vs. spinal fixation plus laminectomy and duroplasty. The primary outcome will be change in AIS motor score at 6 months from baseline with multiple secondary outcomes assessing hand function, walking, urinary and anal sphincters as well as quality of life. DISCUS will have monitoring of ISP pressure and microdialysis from the injury site as optional extras. The study has been funded by the National Institute of Health Research (NIHR) and is currently being set up, aiming to start patient recruitment in July 2021 (https://fundingawards. nihr.ac.uk/award/NIHR130048). DISCUS is not yet registered.

\section{Dogs}

A RCT in dogs is also being established. This will be a multinational multicentre study which aims to recruit 350 dogs with motor and sensory complete thoracolumbar spinal cord injuries. Dogs will be randomized 1:1 to receive either standard extradural decompression (removal of compressing herniated disc material) or undergo both extradural decompression and durotomy over 4 vertebral lengths. Outcome will be recorded as the proportion of dogs recovering to walk at least 10 steps without support (a routine measure of recovery of voluntary locomotion in dogs with severe thoracolumbar SCI). As a secondary outcome the proportion of dogs that develop progressive myelomalacia will also be compared between the two study arms.

\section{DISCUSSION}

Evidence from several animal species and from several types of SCI including contusion-compression in humans, disc prolapse is dogs as well as various experimental SCI models of contusion (weight drop, impactor) and/or compression (aneurysm clip, forceps, balloon) in other mammals suggest that the injured spinal cord swells against the dura. However, the human studies only provide Level III evidence. Some authors have suggested that multi-level laminectomies effectively decompress the cord without the need for duroplasty. Opening the dura after severe SCI improves cord physiological parameters in humans and animals and, in some rodent models, also improves histological and functional outcomes. Overall, we conclude that it is unclear whether opening the dura improves clinical outcomes in humans and dogs. The two RCTs being set up should provide Level I evidence.

\section{AUTHOR CONTRIBUTIONS}

SS wrote the sections on humans and part of the sections on rodents. NJ wrote the sections on dogs and part of the sections on rodents. Both authors have reviewed the entire manuscript.

\section{FUNDING}

SS was supported by the Wings for Life Spinal Cord Research Foundation and research grant NIHR130048 from the UK National Institutes of Health Research. 


\section{REFERENCES}

1. Lee BB, Cripps RA, Fitzharris M, Wing PC. The global map for traumatic spinal cord injury epidemiology: update 2011, global incidence rate. Spinal Cord. (2014) 52:110-6. doi: 10.1038/sc.2012.158

2. Yelamarthy PKK, Chhabra HS, Vaccaro A, Vishwakarma G, Kluger P, Nanda A, et al. Management and prognosis of acute traumatic cervical central cord syndrome: systematic review and Spinal Cord Society-Spine Trauma Study Group position statement. Eur Spine J. (2019) 28:2390407. doi: 10.1007/s00586-019-06085-z

3. Spinal Cord Injury (SCI). 2016 Facts and Figures at a Glance. J Spinal Cord Med. (2016) 39:493-4. doi: 10.1080/10790268.2016.1210925

4. Moore SA, Granger N, Olby NJ, Spitzbarth I, Jeffery ND, Tipold A, et al. Targeting translational successes through CANSORT-SCI: using pet dogs to identify effective treatments for spinal cord injury. J Neurotrauma. (2017) 34:2007-18. doi: 10.1089/neu.2016.4745

5. Goggin JE, Li AS, Franti CE. Canine intervertebral disk disease: characterization by age, sex, breed, and anatomic site of involvement. Am J Vet Res. (1970) 31:1687-92.

6. Smolders LA, Bergknut N, Grinwis GC, Hagman R, Lagerstedt AS, Hazewinkel HA, et al. Intervertebral disc degeneration in the dog. Part 2: chondrodystrophic and non-chondrodystrophic breeds. Vet J. (2013) 195:292-9. doi: 10.1016/j.tvjl.2012.10.011

7. Ball MU, McGuire JA, Swaim SF, Hoerlein BF. Patterns of occurrence of disk disease among registered dachshunds. J Am Vet Med Assoc. (1982) 180:519-22.

8. Brown EA, Dickinson PJ, Mansour T, Sturges BK, Aguilar M, Young AE, et al. FGF4 retrogene on CFA12 is responsible for chondrodystrophy and intervertebral disc disease in dogs. Proc Natl Acad Sci U.S.A. (2017) 114:11476-81. doi: 10.1073/pnas.1709082114

9. Dickinson PJ, Bannasch DL. Current understanding of the genetics of intervertebral disc degeneration. Front Vet Sci. (2020) 7:431. doi: 10.3389/fvets.2020.00431

10. Granger N, Carwardine D. Acute spinal cord injury: tetraplegia and paraplegia in small animals. Vet Clin North Am Small Anim Pract. (2014) 44:113156. doi: 10.1016/j.cvsm.2014.07.013

11. Griffiths IR. The extensive myelopathy of intervertebral disc protrusions in dogs ('the ascending syndrome'). J Small Anim Pract. (1972) 13:42538. doi: 10.1111/j.1748-5827.1972.tb06870.x

12. Balducci F, Canal S, Contiero B, Bernardini M. Prevalence and risk factors for presumptive ascending/descending myelomalacia in dogs after thoracolumbar intervertebral disk herniation. J Vet Intern Med. (2017) 31:498-504. doi: 10.1111/jvim.14656

13. Boudreau CE, Otamendi A, Levine JM, Griffin JF, Gilmour L, Jeffery ND. Relationship between machine-learning image classification of T2-weighted intramedullary hypointensity on 3T MRI and clinical outcome in dogs with severe spinal cord injury. J Neurotrauma. (2020) doi: 10.1089/neu.2020.7188. [Epub ahead of print].

14. Darian-Smith C. Monkey models of recovery of voluntary hand movement after spinal cord and dorsal root injury. ILAR J. (2007) 48:396410. doi: 10.1093/ilar.48.4.396

15. Schomberg DT, Miranpuri GS, Chopra A, Patel K, Meudt JJ, Tellez A, et al. Translational relevance of swine models of spinal cord injury. J Neurotrauma. (2017) 34:541-51. doi: 10.1089/neu.2016.4567

16. Zhang N, Fang $M$, Chen H, Gou F, Ding $M$. Evaluation of spinal cord injury animal models. Neural Regen Res. (2014) 9:2008-12. doi: 10.4103/1673-5374.143436

17. Sharif-Alhoseini M, Khormali M, Rezaei M, Safdarian M, Hajighadery A, Khalatbari MM, et al. Animal models of spinal cord injury: a systematic review. Spinal Cord. (2017) 55:714-21. doi: 10.1038/sc. 2016.187

18. Weiner MF, Silver JR. The origins of the treatment of traumatic spinal injuries. Eur Neurol. (2014) 72:363-9. doi: 10.1159/000365287

19. Fehlings MG, Vaccaro A, Wilson JR, Singh A, W Cadotte D, Harrop JS, et al. Early versus delayed decompression for traumatic cervical spinal cord injury: results of the Surgical Timing in Acute Spinal Cord Injury Study (STASCIS). PLoS ONE. (2012) 7:e32037. doi: 10.1371/journal.pone. 0032037
20. Werndle MC, Zoumprouli A, Sedgwick P, Papadopoulos MC. Variability in the treatment of acute spinal cord injury in the United Kingdom: results of a national survey. J Neurotrauma. (2012) 29:880-8. doi: 10.1089/neu.2011.2038

21. van Middendorp JJ, Hosman AJ, Doi SA. The effects of the timing of spinal surgery after traumatic spinal cord injury: a systematic review and metaanalysis. J Neurotrauma. (2013) 30:1781-94. doi: 10.1089/neu.2013.2932

22. Moore SA, Tipold A, Olby NJ, Stein V, Granger N, Canine Spinal Cord Injury Consortium, (CANSORT SCI). Current approaches to the management of acute thoracolumbar disc extrusion in dogs. Front Vet Sci. (2020) 7:610. doi: $10.3389 /$ fvets.2020.00610

23. Gage ED, Hoerlein BF. Hemilaminectomy and dorsal laminectomy for relieving compressions of the spinal cord in the dog. J Am Vet Med Assoc. (1968) 152:351-9.

24. Jeffery ND. Treatment of acute and chronic thoracolumbar disc disease by 'mini hemilaminectomy'. J Small Animal Pract. (1988) 1988:611-6.

25. Moissonnier P, Meheust P, Carozzo C. Thoracolumbar lateral corpectomy for treatment of chronic disk herniation: technique description and use in 15 dogs. Vet Surg. (2004) 33:620-8. doi: 10.1111/j.1532-950X.2004.04085.x

26. Muguet-Chanoit AC, Olby NJ, Lim JH, Gallagher R, Niman Z, Dillard S, et al. The cutaneous trunci muscle reflex: a predictor of recovery in dogs with acute thoracolumbar myelopathies caused by intervertebral disc extrusions. Vet Surg. (2012) 41:200-6. doi: 10.1111/j.1532-950X.2011.00921.x

27. Tarawneh AM, D’Aquino D, Hilis A, Eisa A, Quraishi NA. Can MRI findings predict the outcome of cervical spinal cord Injury? A systematic review. Eur Spine J. (2020) 29:2457-64. doi: 10.1007/s00586-020-06511-7

28. Saadoun S, Werndle MC, Lopez de Heredia L, Papadopoulos MC. The dura causes spinal cord compression after spinal cord injury. Br J Neurosurg. (2016) 30:582-4. doi: 10.3109/02688697.2016.1173191

29. Saadoun S, Papadopoulos MC. Targeted perfusion therapy in spinal cord trauma. Neurotherapeutics. (2020) 17:51121. doi: 10.1007/s13311-019-00820-6

30. Werndle MC, Saadoun S, Phang I, Czosnyka M, Varsos GV, Czosnyka ZH, et al. Monitoring of spinal cord perfusion pressure in acute spinal cord injury: initial findings of the injured spinal cord pressure evaluation study*. Crit Care Med. (2014) 42:646-55. doi: 10.1097/CCM.0000000000000028

31. Phang I, Papadopoulos MC. Intraspinal pressure monitoring in a patient with spinal cord injury reveals different intradural compartments: injured spinal cord pressure evaluation (ISCoPE) Study. Neurocrit Care. (2015) 23:4148. doi: 10.1007/s12028-015-0153-6

32. Hogg FRA, Gallagher MJ, Kearney S, Zoumprouli A, Papadopoulos MC, Saadoun S. Acute spinal cord injury: monitoring lumbar cerebrospinal fluid provides limited information about the injury site. J Neurotrauma. (2020) 37:1156-64. doi: 10.1089/neu.2019.6789

33. Phang I, Werndle MC, Saadoun S, Varsos G, Czosnyka M, Zoumprouli A, et al. Expansion duroplasty improves intraspinal pressure, spinal cord perfusion pressure, and vascular pressure reactivity index in patients with traumatic spinal cord injury: injured spinal cord pressure evaluation study. J Neurotrauma. (2015) 32:865-74. doi: 10.1089/neu.2014.3668

34. Papadopoulos MC. Intrathecal pressure after spinal cord injury. Neurosurgery. (2015) 77:E500. doi: 10.1227/NEU.0000000000000862

35. Kwon BK, Curt A, Belanger LM, Bernardo A, Chan D, Markez JA, et al. Intrathecal pressure monitoring and cerebrospinal fluid drainage in acute spinal cord injury: a prospective randomized trial. J Neurosurg Spine. (2009) 10:181-93. doi: 10.3171/2008.10.SPINE08217

36. Squair JW, Belanger LM, Tsang A, Ritchie L, Mac-Thiong JM, Parent S, et al. Spinal cord perfusion pressure predicts neurologic recovery in acute spinal cord injury. Neurology. (2017) 89:1660-7. doi: 10.1212/WNL.0000000000004519

37. Grassner L, Winkler PA, Strowitzki M, Buhren V, Maier D, Bierschneider M. Increased intrathecal pressure after traumatic spinal cord injury: an illustrative case presentation and a review of the literature. Eur Spine J. (2017) 26:205. doi: 10.1007/s00586-016-4769-9

38. Zhu F, Yao S, Ren Z, Telemacque D, Qu Y, Chen K, et al. Early durotomy with duroplasty for severe adult spinal cord injury without radiographic abnormality: a novel concept and method of surgical decompression. Eur Spine J. (2019) 28:2275-82. doi: 10.1007/s00586-019-06091-1

39. Hutchinson PJ, Kolias AG, Timofeev IS, Corteen EA, Czosnyka $\mathrm{M}$, Timothy J, et al. Trial of decompressive craniectomy for 
traumatic intracranial hypertension. $N$ Engl $J$ Med. (2016) 375:1119-30. doi: 10.1056/NEJMoa1605215

40. Saadoun S, Bell BA, Verkman AS, Papadopoulos MC. Greatly improved neurological outcome after spinal cord compression injury in AQP4-deficient mice. Brain. (2008) 131:1087-98. doi: 10.1093/brain/awn014

41. Gilmour LJ, Jeffery ND, Miles K, Riedesel E. Single-shot turbo spin echo pulse sequence findings in dogs with and without progressive myelomalacia. Vet Radiol Ultrasound. (2017) 58:197-205. doi: 10.1111/vru.12463

42. Ito D, Matsunaga S, Jeffery ND, Sasaki N, Nishimura R, Mochizuki M, et al. Prognostic value of magnetic resonance imaging in dogs with paraplegia caused by thoracolumbar intervertebral disk extrusion: 77 cases (20002003). J Am Vet Med Assoc. (2005) 227:1454-60. doi: 10.2460/javma.2005. 227.1454

43. Allen AR. Surgery of experimental lesion of spinal cord equivalent to crush injury of fracture dislocation of spinal column. JAMA. (1911) 57:878-80.

44. Parker AJ, Smith CW. Functional recovery from spinal cord trauma following incision of spinal meninges in dogs. Res Vet Sci. (1974) 16:276-9.

45. Loughin CA, Dewey CW, Ringwood PB, Pettigrew RW, Kent M, Budsberg SC. Effect of durotomy on functional outcome of dogs with type I thoracolumbar disc extrusion and absent deep pain perception. Vet Comp Orthop Traumatol. (2005) 18:141-6. doi: 10.1055/s-0038-1632953

46. Coates JR. Intervertebral disk disease. Vet Clin North Am Small Anim Pract. (2000) 30:77-110. doi: 10.1016/s0195-5616(00)50004-7

47. Takahashi F, Honnami A, Toki M, Dosaka A, Fujita Y, Hara Y, et al. Effect of durotomy in dogs with thoracolumbar disc herniation and without deep pain perception in the hind limbs. Vet Surg. (2020) 49:8609. doi: $10.1111 /$ vsu. 13409

48. Jeffery ND, Mankin JM, Ito D, Boudreau CE, Kerwin SC, Levine $\mathrm{JM}$, et al. Extended durotomy to treat severe spinal cord injury after acute thoracolumbar disc herniation in dogs. Vet Surg. (2020) 49:88493. doi: 10.1111/vsu. 13423

49. Aikawa T, Fujita H, Kanazono S, Shibata M, Yoshigae Y. Longterm neurologic outcome of hemilaminectomy and disk fenestration for treatment of dogs with thoracolumbar intervertebral disk herniation: 831 cases (2000-2007). J Am Vet Med Assoc. (2012) 241:1617-26. doi: 10.2460/javma.241.12.1617

50. Langerhuus L, Miles J. Proportion recovery and times to ambulation for non-ambulatory dogs with thoracolumbar disc extrusions treated with hemilaminectomy or conservative treatment: A systematic review and meta-analysis of case-series studies. Vet J. (2017) 220:7-16. doi: 10.1016/j.tvjl.2016.12.008

51. Freeman P, Jeffery ND. Re-opening the window on fenestration as a treatment for acute thoracolumbar intervertebral disc herniation in dogs. J Small Anim Pract. (2017) 58:199-204. doi: 10.1111/jsap.12653

52. Khaing ZZ, Cates LN, Fischedick AE, McClintic AM, Mourad PD, Hofstetter CP. Temporal and spatial evolution of raised intraspinal pressure after traumatic spinal cord injury. J Neurotrauma. (2017) 34:64551. doi: 10.1089/neu.2016.4490

53. Dong X, Yang D, Li J, Liu C, Yang M, Du L, et al. Intramedullary pressure changes in rats after spinal cord injury. Spinal Cord. (2016) 54:94750. doi: $10.1038 / \mathrm{sc} .2016 .35$

54. Awwad W, Bassi M, Shrier I, Al-Ahaideb A, Steele RJ, Jarzem PF. Mitigating spinal cord distraction injuries: the effect of durotomy in decreasing cord interstitial pressure in vitro. Eur J Orthop Surg Traumatol. (2014) 24 Suppl 1:261. doi: 10.1007/s00590-013-1409-5

55. Zhang J, Wang H, Zhang C, Li W. Intrathecal decompression versus epidural decompression in the treatment of severe spinal cord injury in rat model: a randomized, controlled preclinical research. J Orthop Surg Res. (2016) 11:34. doi: 10.1186/s13018-016-0369-y

56. Jalan D, Saini N, Zaidi M, Pallottie A, Elkabes S, Heary RF. Effects of early surgical decompression on functional and histological outcomes after severe experimental thoracic spinal cord injury. J Neurosurg Spine. (2017) 26:62-75. doi: 10.3171/2016.6.SPINE16343
57. Smith JS, Anderson R, Pham T, Bhatia N, Steward O, Gupta R. Role of early surgical decompression of the intradural space after cervical spinal cord injury in an animal model. J Bone Joint Surg Am. (2010) 92:120614. doi: 10.2106/JBJS.I.00740

58. Fernandez E, Pallini R. Connective tissue scarring in experimental spinal cord lesions: significance of dural continuity and role of epidural tissues. Acta Neurochir (Wien). (1985) 76:145-8. doi: 10.1007/BF014 18478

59. Leonard AV, Thornton E, Vink R. The relative contribution of edema and hemorrhage to raised intrathecal pressure after traumatic spinal cord injury. J Neurotrauma. (2015) 32:397-402. doi: 10.1089/neu. 2014.3543

60. Saadoun S, Chen S, Papadopoulos MC. Intraspinal pressure and spinal cord perfusion pressure predict neurological outcome after traumatic spinal cord injury. J Neurol Neurosurg Psychiatry. (2017) 88:452-3. doi: 10.1136/jnnp-2016-314600

61. Griffiths IR. Vasogenic edema following acute and chronic spinal cord compression in the dog. J Neurosurg. (1975) 42:155-65. doi: 10.3171/jns.1975.42.2.0155

62. Zhang JS, Huan Y. Multishot diffusion-weighted MR imaging features in acute trauma of spinal cord. Eur Radiol. (2014) 24:685-92. doi: 10.1007/s00330-013-3051-3

63. Kimura A, Hsu M, Seldin M, Verkman AS, Scharfman HE, Binder DK. Protective role of aquaporin-4 water channels after contusion spinal cord injury. Ann Neurol. (2010) 67:794-801. doi: 10.1002/ana.22023

64. Fleming JC, Norenberg MD, Ramsay DA, Dekaban GA, Marcillo AE, Saenz $\mathrm{AD}$, et al. The cellular inflammatory response in human spinal cords after injury. Brain. (2006) 129:3249-69. doi: 10.1093/brain/awl296

65. Orr MB, Gensel JC. Spinal cord injury scarring and inflammation: therapies targeting glial and inflammatory responses. Neurotherapeutics. (2018) 15:54153. doi: 10.1007/s13311-018-0631-6

66. Harwell DM, Gibson JL, Fessler RD, Holtz J, Pettigrew DB, Kuntz C. Pia mater significantly contributes to spinal cord intraparenchymal pressure in a simulated model of edema. Spine. (2016) 41:524. doi: 10.1097/BRS.0000000000001306

67. Zhang X, Jing Y, Qin C, Liu C, Yang D, Gao F, et al. Mechanical stress regulates autophagic flux to affect apoptosis after spinal cord injury. J Cell Mol Med. (2020) 24:12765-76. doi: 10.1111/jcmm.15863

68. Khaing ZZ, Cates LN, Dewees DM, Hyde JE, Gaing A, Birjandian Z, et al. The effect of durotomy versus myelotomy on tissue sparing and functional outcome after spinal cord injury. $J$ Neurotrauma. (2020) doi: 10.1089/neu.2020.7297. [Epub ahead of print].

69. Aarabi B, Olexa J, Chryssikos T, Galvagno SM, Hersh DS, Wessell A, et al. Extent of Spinal Cord Decompression in Motor Complete (American Spinal Injury Association Impairment Scale Grades A and B) Traumatic Spinal Cord Injury Patients: Post-Operative Magnetic Resonance Imaging Analysis of Standard Operative Approaches. J Neurotrauma. (2019) 36:862876. doi: 10.1089/neu.2018.5834

70. Hogg FRA, Gallagher MJ, Chen S, Zoumprouli A, Papadopoulos MC, Saadoun S. Predictors of intraspinal pressure and optimal cord perfusion pressure after traumatic spinal cord injury. Neurocrit Care. (2019) 30:4218. doi: 10.1007/s12028-018-0616-7

Conflict of Interest: The authors declare that the research was conducted in the absence of any commercial or financial relationships that could be construed as a potential conflict of interest.

Copyright (C) 2021 Saadoun and Jeffery. This is an open-access article distributed under the terms of the Creative Commons Attribution License (CC BY). The use, distribution or reproduction in other forums is permitted, provided the original author(s) and the copyright owner(s) are credited and that the original publication in this journal is cited, in accordance with accepted academic practice. No use, distribution or reproduction is permitted which does not comply with these terms. 